OPEN ACCESS

Check for updates

\title{
Neurodevelopmental outcomes at age 5 among children born preterm: EPIPAGE-2 cohort study
}

\author{
Véronique Pierrat, ${ }^{1,2}$ Laetitia Marchand-Martin, ${ }^{1}$ Stéphane Marret, ${ }^{3,4}$ Catherine Arnaud, $, 5,6$ \\ Valérie Benhammou, ${ }^{1}$ Gilles Cambonie, ${ }^{8}$ Thierry Debillon, ${ }^{9,10}$ Marie-Noëlle Dufourg, ${ }^{11}$ \\ Catherine Gire, ${ }^{12}$ François Goffinet, ${ }^{1,13}$ Monique Kaminski, ${ }^{1}$ Alexandre Lapillonne, ${ }^{14}$ \\ Andrei Scott Morgan, ${ }^{1,15}$ Jean-Christophe Rozé, ${ }^{16,17}$ Sabrina Twilhaar, ${ }^{1}$ Marie-Aline Charles, ${ }^{9,18}$ \\ Pierre-Yves Ancel, ${ }^{1,19}$ on behalf of the EPIPAGE-2 writing group
}

For numbered affiliations see end of the article.

Correspondence to: $\mathrm{V}$ Pierrat, Tenon Hospital, Equipe EPOPé, U1153, 4 Rue de la Chine, 75020 Paris, France veronique.pierrat@inserm.fr (ORCID 0000-0001-7435-5144)

Additional material is published online only. To view please visit the journal online.

Cite this as: $B M / 2021 ; 372: n 741$ http://dx.doi.org/10.1136/bmj.n741

Accepted: 4 March 2021

\section{ABSTRACT}

OBJECTIVES

To describe neurodevelopment at age 5 among children born preterm.

DESIGN

Population based cohort study, EPIPAGE-2.

SETTING

France, 2011.

PARTICIPANTS

4441 children aged $51 / 2$ born at 24-26, 27-31, and 32-34 weeks

\section{MAIN OUTCOME MEASURES}

Severe/moderate neurodevelopmental disabilities, defined as severe/moderate cerebral palsy (Gross Motor Function Classification System (GMFCS) $\geq 2$ ), or unilateral or bilateral blindness or deafness, or full scale intelligence quotient less than minus two standard deviations (Wechsler Preschool and Primary Scale of Intelligence, 4th edition). Mild neurodevelopmental disabilities, defined as mild cerebral palsy (GMFCS-1), or visual disability $\geq 3.2 / 10$ and $<5 / 10$, or hearing loss $<40 \mathrm{~dB}$, or full scale intelligence quotient (minus two to minus one standard deviation) or developmental coordination disorders (Movement Assessment Battery for Children, 2nd edition, total score less than or equal to the fifth centile), or behavioural difficulties (strengths and difficulties questionnaire, total score greater

\section{WHAT IS ALREADY KNOWN ON THIS TOPIC}

Children born preterm experience difficulties in many developmental domains, with consequences for education, adaptive behaviour, and parental concerns Neurodevelopmental disabilities at preschool age are usually described using a composite outcome including cerebral palsy, sensory and cognitive deficits Rates of co-occurring problems, such as developmental coordination disorders or behavioural difficulties, in preterm children usually classified as having no, or mild, neurodevelopmental disabilities, are not readily available

\section{WHAT THIS STUDY ADDS}

In France in 2011, children born extremely preterm and also those born very and moderately preterm remain at high risk of severe/moderate neurodevelopmental disabilities

Inclusion of behavioural difficulties and developmental coordination disorders in the definition of mild neurodevelopmental disabilities describes in more depth the complexity of difficulties faced by this group of children born preterm

Educational assistance and complex developmental interventions were used in all groups of children born preterm and with varying levels of disability, including those with mild or no apparent disabilities at age $51 / 2$ than or equal to the 90th centile), school assistance (mainstream class with support or special school), complex developmental interventions, and parents' concerns about development. The distributions of the scores in contemporary term born children were used as reference. Results are given after multiple imputation as percentages of outcome measures with exact binomial 95\% confidence intervals.

\section{RESULTS}

Among 4441 participants, 3083 (69.4\%) children were assessed. Rates of severe/moderate neurodevelopmental disabilities were $28 \%$ (95\% confidence interval $23.4 \%$ to $32.2 \%), 19 \%$ (16.8\% to $20.7 \%$ ), and $12 \%$ (9.2\% to $14.0 \%$ ) and of mild disabilities were $38.5 \%$ (33.7\% to $43.4 \%$ ), $36 \%$ (33.4\% to $38.1 \%$ ), and $34 \%$ (30.2\% to $37.4 \%$ ) at $24-$ $26,27-31$, and $32-34$ weeks, respectively. Assistance at school was used by $27 \%$ (22.9\% to $31.7 \%), 14 \%$ (12.1\% to $15.9 \%)$, and $7 \%$ (4.4\% to $9.0 \%)$ of children at 24-26, 27-31, and 32-34 weeks, respectively. About half of the children born at $24-26$ weeks (52\% (46.4\% to $57.3 \%)$ ) received at least one developmental intervention which decreased to $26 \%(21.8 \%$ to $29.4 \%$ ) for those born at 32-34 weeks. Behaviour was the concern most commonly reported by parents. Rates of neurodevelopment disabilities increased as gestational age decreased and were higher in families with low socioeconomic status.

\section{CONCLUSIONS}

In this large cohort of children born preterm, rates of severe/moderate neurodevelopmental disabilities remained high in each gestational age group. Proportions of children receiving school assistance or complex developmental interventions might have a significant impact on educational and health organisations. Parental concerns about behaviour warrant attention.

\section{Introduction}

Children born preterm may experience many developmental difficulties, varying from severe to subtle impairments. ${ }^{1}{ }^{2}$ Most of these deficits are better identified after age 2, when higher order cognitive, language, and behavioural processes develop and affect early sensorimotor abilities. Neurodevelopmental disabilities in early childhood are commonly reported as a composite outcome of cerebral palsy, sensory and cognitive impairments. ${ }^{3-6}$ More subtle deficits, such as behavioural difficulties or developmental coordination disorders, are 
usually reported separately, ${ }^{7-10}$ even though they may alter a child's socioemotional competencies, affect daily activities and school outcomes, disturb family functioning, and require substantial medical, social, educational, and family support. ${ }^{11}$ Thus it is important that all conditions are considered together. Additionally, the parents' viewpoint is increasingly recognised as essential to help bridge gaps between the information parents desire on outcomes and that which has traditionally been offered to them. ${ }^{12} 13$

Advances in perinatal intensive care, including increased use of antenatal corticosteroids, of exogenous surfactant, of non-invasive respiratory support, and avoidance of the liberal use of postnatal corticosteroids to treat bronchopulmonary dysplasia, ${ }^{14}$ have led to increased survival of infants born preterm and particularly those born extremely preterm (2426 weeks). ${ }^{15}{ }^{16}$ Recent large population based studies reporting outcomes in early childhood have mainly focused on those born extremely preterm. ${ }^{35617}$ Long term outcomes in this group have not convincingly improved. ${ }^{14}$ Children born very (27-31 weeks) or moderately (32-34) preterm have generated less research, ${ }^{18}$ but changes in care have also been substantial for these infants, who represent larger proportions of those facing developmental difficulties. Up to date data are thus essential for evaluating their needs and providing stakeholders with useful information.

The EPIPAGE-2 cohort is a national cohort designed to investigate outcomes for children born below 35 weeks in 2011 in France. ${ }^{19}$ Improvements in survival, neonatal outcomes, and neurosensory disabilities at age 2 have already been shown between the 1997 EPIPAGE cohort and EPIPAGE-2. ${ }^{16}{ }^{20}$ We then conducted an assessment at age $51 / 2$. The aim of the present study was to describe neurodevelopmental outcomes, including cerebral palsy, sensory impairments, and cognition, as well as behavioural difficulties and developmental coordination disorders, for children included in the EPIPAGE-2 follow-up using contemporary children born at term as a reference. To further assess the family and social burden of prematurity, we also report educational assistance, use of complex developmental interventions, ${ }^{21}$ and parental concerns about development.

\section{Methods}

Study design

EPIPAGE-2 is a French prospective national population based cohort of preterm born children. All births at 22 to 34 weeks' gestation in all maternity units in 25 French regions ( 21 of the 22 metropolitan regions and all overseas regions) were eligible for inclusion. The study began on 28 March 2011. We recruited infants born at 22-26 weeks during an eight month period, those born at 27-31 weeks during a six month period, and those born at 32-34 weeks, during a five week period. ${ }^{19}$ All survivors were invited to participate in a comprehensive neurodevelopmental assessment at age $5 \frac{1}{2} 2$. To obtain reference data for the various developmental tests used in this study and describe outcomes for the $5 \frac{1}{2} 2$ year old EPIPAGE- 2 cohort, we aimed to assess term born children from the ELFE (Étude Longitudinale Française depuis l'Enfance) cohort with the EPIPAGE-2 follow-up protocol. The ELFE cohort is a contemporary French cohort of more than 18000 children born after 32 weeks in 2011, in 344 randomly selected public and private maternity units in metropolitan France. ${ }^{22}$ For financial and organisational reasons, the assessment could be offered only to 600 children born at term from the ELFE cohort. The size of this reference group was sufficient to obtain good precision for estimated scores of the main scales used based on known means and standard deviations (web appendix 1). Consent for participation was obtained from parents of 592 of the 600 selected term born children.

\section{Data collection}

Assessments included an interview with parents, a self-administered parental questionnaire, clinical examination by a paediatrician, and an evaluation by a psychologist, performed in 110 centres specifically opened for the study. Paediatricians and psychologists were trained to ensure homogeneity in their evaluations. Assessors were not blinded to the child's gestational age. If the child was too disabled to participate, parental permission was sought to contact rehabilitation centres to provide information enabling classification of disabilities. In one region (accounting for 13 subjects), and elsewhere for parents refusing formal assessment or if the assessment team was not available, parents were asked to complete a postal questionnaire including information on cerebral palsy, severe/moderate sensory disabilities, school attendance, and use of complex developmental interventions.

\section{Neurodevelopmental evaluation}

Description and classification of variables used to describe neurodevelopment and classification of neurodevelopmental disabilities are described in table 1.

Motor domain-motor function was evaluated during the clinical examination, designed to screen cerebral palsy and developmental coordination disorders. Cerebral palsy was reported according to the diagnostic criteria of the Surveillance of Cerebral Palsy in Europe network, ${ }^{23}$ and graded using the Gross Motor Function Classification System (GMFCS). ${ }^{24}$ Developmental coordination disorders were defined as a total score less than or equal to the fifth centile of the reference sample on the Movement Assessment Battery for Children, second edition, ${ }^{25}$ in those children of the reference sample who did not have cerebral palsy, severe/moderate sensory disability, or a full scale intelligence quotient score less than two standard deviations below the mean.

Sensory domain-we based assessments of hearing and vision on interviews with parents and medical records available during the clinical examination. Visual acuity was evaluated with the Sander-Zalonghi 
scale. $^{26}$ Degree of visual disability was classified according to World Health Organization criteria, ${ }^{27}$ and hearing disability according to the severity of hearing loss and the need for hearing aids. ${ }^{28}$

Cognitive domain-we used the French version of the Wechsler Preschool and Primary Scale of Intelligence, fourth edition, ${ }^{29}$ which measures cognitive ability in five domains (verbal comprehension, visuospatial indices, fluid reasoning, working memory, processing speed), resulting in a composite full scale intelligence quotient reflecting the overall level of intelligence. Results are reported as mean and standard deviations, and by categories using cut-off points according to the mean and standard deviations of the reference sample.

Behaviour-we used the strengths and difficulties questionnaire, ${ }^{30}$ a self-administered parental questionnaire designed to screen for symptoms of hyperactivity inattention, emotional, conduct, and peer problems. A total score is calculated by summing the scores of each domain, with a higher score indicating more difficulties. The questionnaire is not used for diagnosis. Children with a total score greater than or equal to the 90th centile of a reference sample, however, are usually considered as having a substantially raised probability of formally diagnosed mental health problems. ${ }^{31}$
Classification of neurodevelopmental disabilities Information on cerebral palsy, sensory deficits, cognitive, behavioural, and motor coordination functioning were combined into a composite measure with four levels of neurodevelopmental disabilities (table 1). Severe and moderate disabilities were primarily based on the severity of cerebral palsy, sensory impairment, and cognitive deficiency, as their presence rules out a diagnosis of developmental coordination disorders, and comorbid behavioural difficulties are highly prevalent. Both developmental coordination disorders and behavioural difficulties were included in the classification of mild neurodevelopmental disabilities.

\section{Education, complex developmental interventions,} and parental concerns

Parents were asked about education, use of complex developmental interventions, and concerns about their child's development to better understand the effect of developmental outcomes on daily family functioning. Variables collected, recorded as binary (yes/no) unless specified, were school enrolment and, if yes, type of school (mainstream class without support, mainstream class with support-defined as either part or full time face to face learning support provided by a dedicated professional-or special

\begin{tabular}{|c|c|}
\hline $\begin{array}{l}\text { Neurodevelopmental } \\
\text { outcome measure }\end{array}$ & Definition or classification \\
\hline \multicolumn{2}{|c|}{ Cerebral palsy-medical examination (or postal questionnaire completed by parents): } \\
\hline Severe & GMFCS level 4/5 or [cerebral palsy unable to walk] \\
\hline Moderate & GMFCS level $2 / 3$ or [cerebral palsy walking unsteadily or with aid] \\
\hline Mild & GMFCS level 1 or [cerebral palsy walking without aid and without restriction] \\
\hline None & No cerebral palsy \\
\hline \multicolumn{2}{|c|}{ Developmental coordination disorders - movement assessment battery for children (second edition): } \\
\hline & Total M-ABC2 score $\leq 5$ th centile (cut-off point $\leq 5$ )* \\
\hline \multicolumn{2}{|c|}{ Visual disability-visual acuity measured with the Sander-Zanlonghi scale and with glasses if needed (or postal questionnaire completed by parents): } \\
\hline Severe & Bilateral binocular visual acuity <1/10 or (blindness) \\
\hline Moderate & Bilateral binocular visual acuity $<3.2 / 10$ but $\geq 1 / 10$ (not available if parentally reported) \\
\hline Mild & Binocular visual acuity $<5 / 10$ but $\geq 3.2 / 10$ (not available if parentally reported) \\
\hline None & Binocular visual acuity $\geq 5 / 10$ or (eye consultation within the past 12 months and vision reported as normal) \\
\hline \multicolumn{2}{|c|}{ Hearing disability-completed during clinical examination or [postal questionnaire completed by parents]: } \\
\hline Severe & Unilateral or bilateral hearing loss ( $>70 \mathrm{~dB}$ ) not corrected or partially corrected with hearing aid (or deafness) \\
\hline Moderate & Unilateral or bilateral hearing loss (40-70 dB) not corrected or partially corrected with hearing aid (not available if parentally reported) \\
\hline Mild & Hearing loss $\leq 40 \mathrm{~dB}$ (not available if parentally reported) \\
\hline None & No hearing loss or hearing reported as normal \\
\hline \multicolumn{2}{|c|}{ Cognitive deficiency-full scale intelligence quotient evaluated with the WPPSI-IV: } \\
\hline Severe & FSIQ $<66$ ( $(-3$ standard deviationst) \\
\hline Moderate & FSIQ 66-78 ( -3 to $<-2$ standard deviationst) \\
\hline Mild & FSIQ 79-92 (-2 to <-1 standard deviationt) \\
\hline None & FSIQ 93-119 ( -1 to +1 standard deviationt) or $\geq 120$ ( 21 standard deviationt) \\
\hline \multicolumn{2}{|c|}{ Behavioural difficulties-strengths and difficulties questionnaire (SDQ) completed by parents: } \\
\hline \multicolumn{2}{|c|}{ Total SDQ score $\geq 90$ th centile (cut-off point $\geq 19$ ) $\dagger$} \\
\hline \multicolumn{2}{|c|}{ Classification of overall neurodevelopmental disabilities: } \\
\hline Severe & At least one of severe cerebral palsy, visual, hearing, or cognitive deficiency \\
\hline Moderate & At least one of moderate cerebral palsy, visual, hearing, or cognitive deficiency \\
\hline Mild & At least one of mild cerebral palsy, visual, hearing, cognitive deficiency, behavioural difficulties, or developmental coordination disorders \\
\hline None & Not classified as severe, moderate, or mild using the above definitions \\
\hline $\begin{array}{l}\text { GMFCS=Gross Motor Funct } \\
\text { questionnaire }{ }^{30} \text {; WPPSI-IV } \\
\text { Definitions in square brack } \\
\text { *Cut-off points were detern } \\
\text { hearing disabilities, and fu } \\
\text { tCut-off point determined }\end{array}$ & $\begin{array}{l}\text { on Classification System }{ }^{24} ; \mathrm{FSIQ}=\text { full scale intelligence quotient; } \mathrm{MABC}-2=\text { Movement Assessment Battery for Children, } 2 \text { nd edition }{ }^{25} ; \mathrm{SDQ}=\mathrm{strengths} \text { and difficulties } \\
\text { Wechsler Preschool and Primary Scale of Intelligence, fourth edition. }{ }^{29} \\
\text { ets are those used from data collected with the postal questionnaire. } \\
\text { ined in relation to distributions from the reference group born at term ( } 37-41 \text { weeks) after exclusion of children with cerebral palsy, severe or moderate vision or } \\
\text { I scale intelligence quotient less than two standard deviations below the mean (web appendix } 1 \text { ). } \\
\text { n relation to distribution of the reference sample born at term ( } 37-41 \text { weeks; web appendix 1). }\end{array}$ \\
\hline
\end{tabular}


schooling-specifically adapted for disabled children); use of complex developmental interventions (at least two visits during the preceding 12 months to a psychologist or psychiatrist, orthoptist, speech therapist, occupational therapist, or physiotherapist) or care in a rehabilitation centre; a request for assistance made to a Maison Départementale des Personnes Handicapées, a French institution that provides additional support for disabled children (specialised health or educational services) or financial support for parents. Finally, parents indicated whether or not they had concerns about their child's language, coordination of movements, learning, or behaviour.

\section{Data management and statistics}

Results among survivors at 51/2 years are presented according to groups of gestational age at birth (2426, 27-31, and 32-34 weeks). Firstly, summary data on child (sex, small for gestational age ${ }^{32}$ ) and maternal characteristics at birth (age, country of birth, cohabitation status, level of education, and parental socioeconomic status), obstetric factors (primiparous, multiple pregnancy, antenatal steroids, caesarean section), the neonatal period (severe neonatal morbidities, including severe bronchopulmonary dysplasia, necrotising enterocolitis (Bell stages 2-3), retinopathy of prematurity stage $>3$, or any intraventricular haemorrhage grade IIIIV or cystic periventricular leukomalacia on cranial ultrasonography ${ }^{16}$ ), and outcome at 2 years (cerebral palsy, a score below threshold in at least one domain of the Ages and Stages Questionnaire ${ }^{33}$ ) were compared between children seen and not seen at follow-up. Those children having formal assessments were also compared with those who completed postal questionnaires only.

Secondly, we present proportions of cerebral palsy, severe/moderate sensory disabilities, cognitive deficiencies, behavioural difficulties, developmental coordination disorders, and level of neurodevelopmental disabilities by gestational groups. To better describe the group with mild disabilities and allow international comparisons, the different co-occurrences of impaired domains are reported. Survival, survival without severe/moderate neurodevelopmental disabilities, and survival without such disabilities among live births are then reported by weeks of gestational age at birth.

Finally, school assistance, use of complex developmental interventions, and parental concerns are described.

Percentages are given with exact 95\% binomial confidence intervals, and means with standard deviations. We present results for complete cases and after multiple imputation to account for selective dropouts and missing information at follow-up. Variables in the imputation model included both those potentially predicting non-response and those predicting outcomes (web appendix 2). We included a large number of predictors to make the assumption, missing at random, more plausible and ensure reliable imputed results. Data were imputed by chained equations using the SAS multiple imputation procedure. ${ }^{34}$ Predictive mean matching was used for continuous variables with missing values, logistic regression for binary variables, and multinomial regression for categorical variables.

We generated 50 independent imputed datasets with 30 iterations each. Estimates were pooled according to Rubin's rule. ${ }^{35}$ We compared gestational age groups using either a test for linear trend, with gestational age group as a continuous variable, or using a $\chi^{2}$ test for categorical variables. All tests used generalised estimating equation models to account for the non-independence of outcomes related to multiple births. The reference sample was weighted to account for the sampling method and socioeconomic characteristics related to identified selection biases present at inclusion and arising from subsequent attrition, to provide a representative population sample (web appendix 1). Factors associated with neurodevelopmental disabilities were studied using multinomial generalised estimating equation logistic regression models, children without disabilities being the reference. Model covariates were gestational age, sex, single or multiple pregnancy status, small for gestational age, and parental socioeconomic status. All tests were two-sided; a P value less than 0.05 was considered statistically significant. Statistical analyses were performed using SAS version 9.4 and R 3.6.1 software.

\section{Patient and public involvement}

Patients were not involved in setting research questions or outcome measures, nor were they involved in design of the study. Parents of children in the EPIPAGE-2 cohort showed overwhelming support for the study through continuing attendance for follow-up. Contact with parents is maintained through newsletters and websites (https://epipage2.inserm.fr/;https://www. elfe-france.fr/). National parents' associations assist with the dissemination of results.

\section{Results}

\section{Population}

Participation in the study from birth to five years' follow-up is shown in figure 1. At age 51/2, 4441 children were alive, and 3083 (69.4\%) were included in the study. Children lost to follow-up were more frequently female, born at 32-34 weeks, and to mothers with lower socioeconomic status (web appendix 3). These children were also more often diagnosed with cerebral palsy when born at 24-26 weeks, and with an Ages and Stages Questionnaire score below the threshold for children born at 27-31 weeks. Children with postal responses only were more often born to mothers of lower socioeconomic status, and had similar neonatal characteristics, but higher proportions of severe/moderate visual disabilities than children with data collected during a clinical examination (web appendix 4). 
EPIPAGE-2

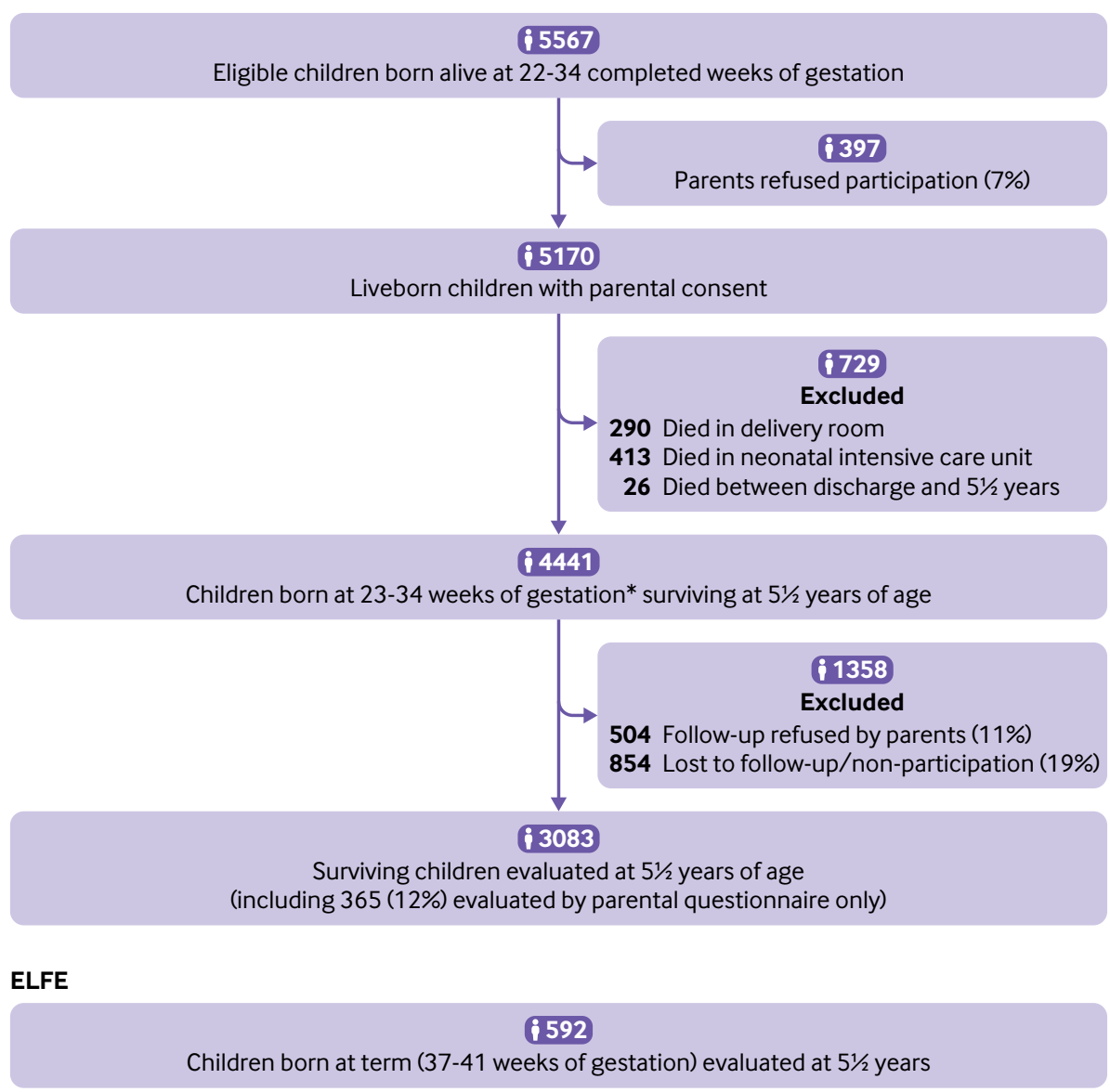

Fig 1 | Study population. *No survivors were born at 22 weeks and only one survivor was born at 23 weeks, who was lost to follow-up at $51 / 2$ years. ELFE= Étude Longitudinale Française depuis l'Enfance

\section{Neurodevelopmental outcomes among children born preterm}

Neurodevelopmental outcomes are presented in table 2. At 24-26, 27-31, and 32-34 weeks' gestational age, cerebral palsy decreased from $12.4 \%$ to $5.9 \%$ and $2.4 \%$ and mean (standard deviation) full scale intelligence quotient increased from 89.6 (16.6) to 93.6 (15.7) and 97.3 (15.0). Behavioural difficulties were reported less often as gestational age increased, from $12.0 \%$ at $24-26$ weeks to $8.2 \%$ at $32-34$ weeks. Proportions of children with developmental coordination disorders were $18.8 \%, 8.5 \%$, and $5.0 \%$ at 24-26, 27-31, and 32-34 weeks, respectively. Severe/ moderate neurodevelopmental disabilities were reported in $27.8 \%, 18.7 \%$, and $11.6 \%$ of children at 24-26, 27-31, and 32-34 weeks, respectively, whereas proportions of children with mild disabilities were $38.5 \%, 35.7 \%$, and $33.8 \%$. Including behavioural difficulties and developmental coordination disorders in the definition of mild neurodevelopmental disabilities increased proportions by $5 \%$ to $7 \%$ among the different gestational age groups (web appendix 5). Most of these children had a combination of cerebral palsy GMFCS-1, and mild sensory or cognitive impairments; behavioural difficulties or developmental coordination disorders were seen only in $18.0 \%, 16.2 \%$, and $15.1 \%$ of children born at 24-26, 27-31, and 32-34 weeks, respectively. Outcomes by week of gestational age at birth are presented in figure 2 for live births according to the level of neurodevelopmental disabilities, and in figure 3 for cerebral palsy, severe/moderate cognitive impairment, and severe/moderate disabilities for survivors at age $5 \frac{1}{2}$.

\section{Education and use of complex developmental interventions}

School enrolment was almost universal across gestational age groups, but proportions of children in a mainstream class without support increased with gestational age, from $72.7 \%$ to $86.0 \%$ and $93.3 \%$ at 24-26, 27-31, and 32-34 weeks, respectively (table 3). School support in mainstream class or special school increased with the level of neurodevelopmental disabilities but was not universal in children with severe/moderate disabilities and was also seen in children with mild, or without, disabilities. Considerable proportions of children had at least one complex developmental intervention during the year before the evaluation. Use of complex developmental interventions increased with the level of neurodevelopmental disabilities but was reported 


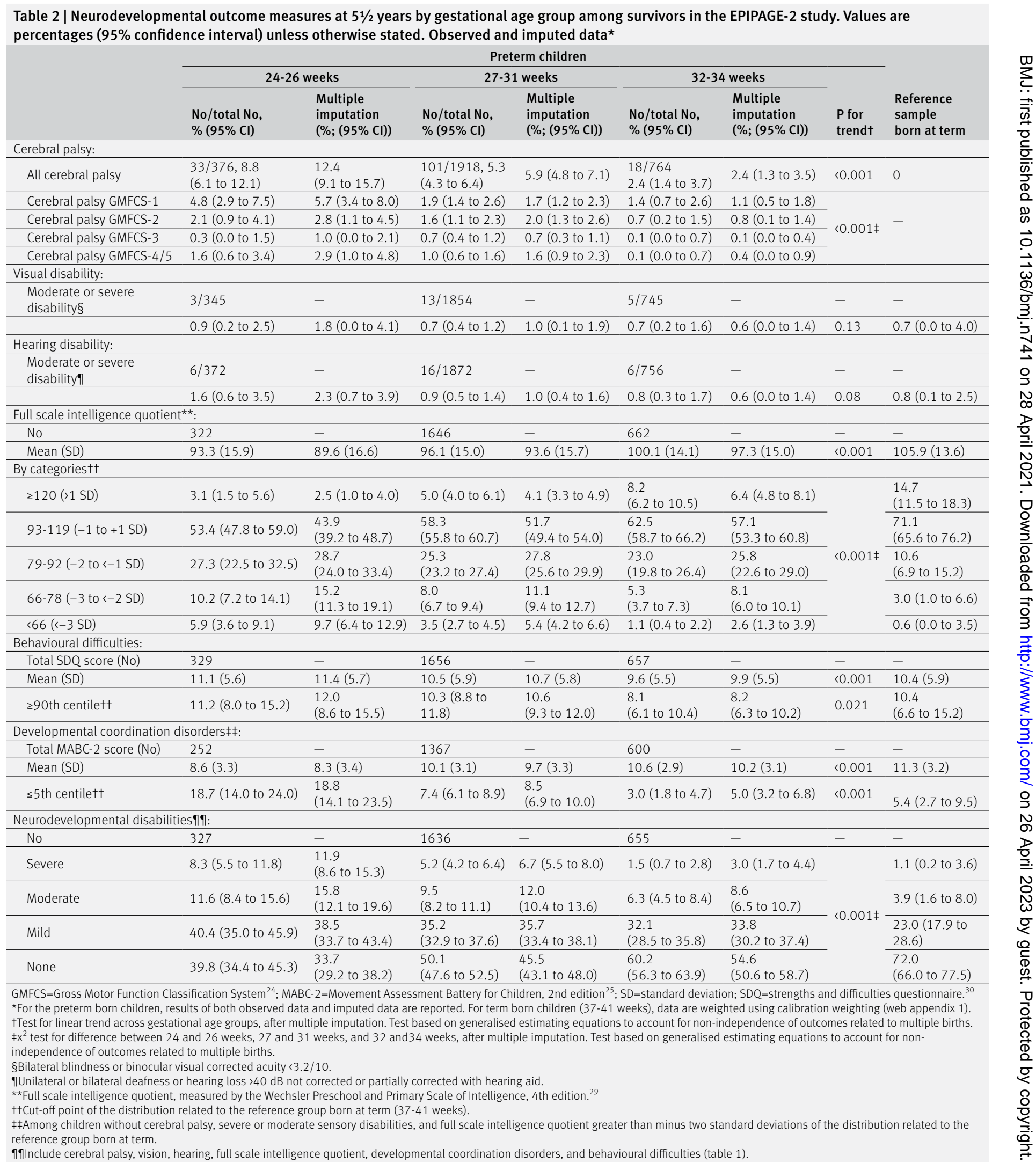

at 24-26 weeks in around half of the children with mild disabilities and one third of those with no disabilities. Among children with severe/moderate neurodevelopmental disabilities, $30 \%$ to $40 \%$ had no interventions. Finally, requests to the Maison Départementale des Personnes Handicapées were reported for $31.1 \%, 17.1 \%$, and $7.8 \%$ of children born at 24-26, 27-31, and 32-34 weeks, respectively. 


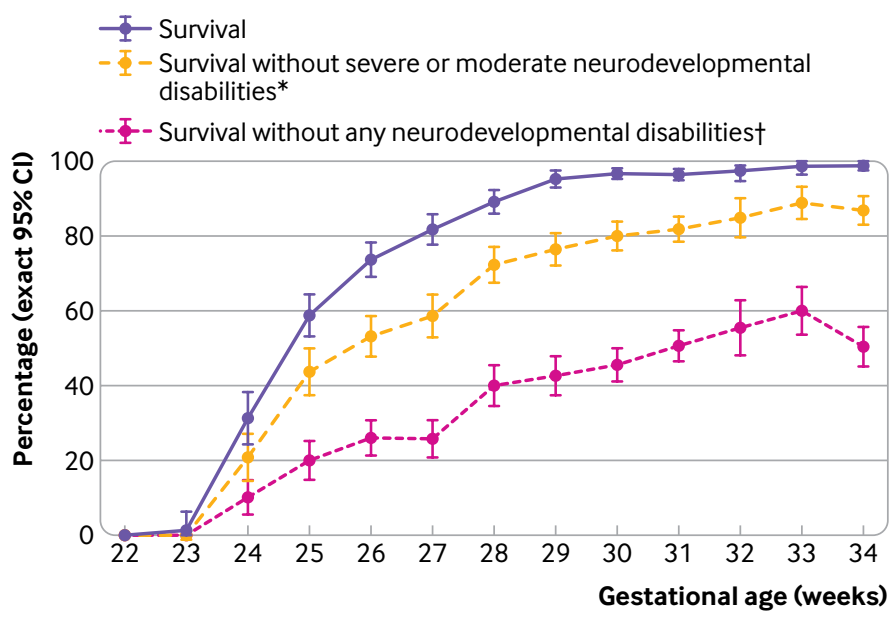

Fig 2 | Survival at 51/2 years, survival without severe/moderate neurodevelopmental disabilities, and survival without any neurodevelopmental disabilities by week of gestational age at birth, among preterm born children in the EPIPAGE-2 study. Data corrected for study design and respondent selection. * Severe or moderate cerebral palsy (Gross Motor Function Classification System level 2-5), vision (bilateral binocular visual acuity $<3.2 / 10$ ), hearing (unilateral-bilateral hearing loss $\geq 40 \mathrm{~dB}$ not corrected or partially corrected with hearing aid), and full scale intelligence quotient less than two standard deviations below the mean of the reference sample born at term (web appendix 1). Includes no cerebral palsy, no vision or hearing disabilities, full scale intelligence quotient greater than or equal to one standard deviation below the mean, no developmental coordination disorder, and no behavioural difficulties (table 1). $\mathrm{Cl}=$ confidence interval had no disabilities, reported concerns in at least one domain.

\section{ELFE reference sample}

After weighting, maternal level of education, maternal socioeconomic status, and paternal socioeconomic status were slightly higher in the reference sample than in the total ELFE cohort (web appendix 1). Parents of children in the ELFE reference sample reported the child's health as being "good" less often than in the total ELFE cohort. They also reported more behavioural difficulties and greater use of complex developmental interventions, with psychological/ psychiatric interventions and speech therapy being the most common.

\section{Factors associated with neurodevelopment disabilities}

Rates of neurodevelopmental disabilities were higher as gestational age decreased, in boys, in children born small for gestational age, and with decreasing parental socioeconomic status (table 5). In families with the lowest socioeconomic status, the adjusted odds ratio for children with mild and severe/moderate disabilities in comparison with children with no disabilities were, respectively, 3.16 (95\% confidence interval 2.35 to 4.25) and 8.80 (5.97 to 12.96).

\section{Discussion}

Parental concerns about development

Parental concerns about development increased as gestational age decreased and with increased level of neurodevelopmental disabilities (table 4). Behavioural concerns were the most common in all gestational age groups. Around half of parents of children with mild disabilities, and a quarter of parents whose children

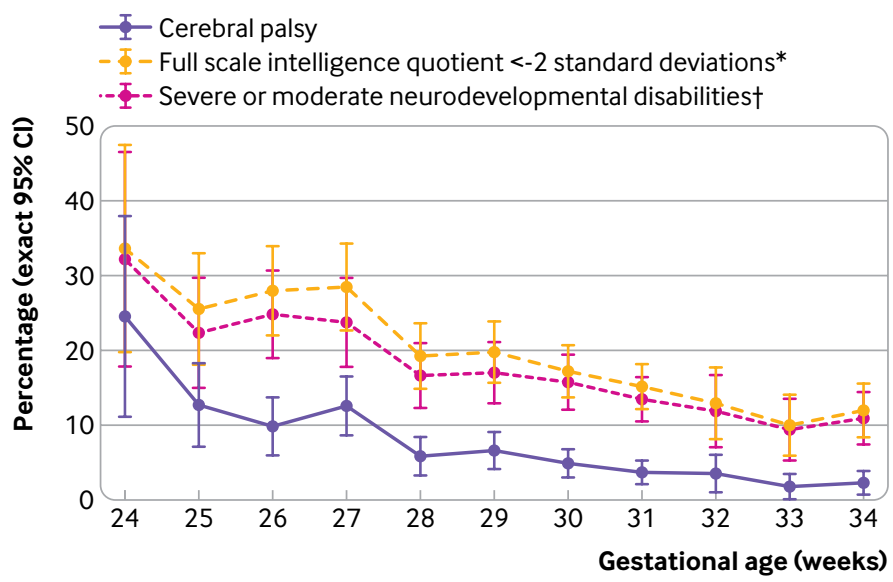

Fig 3 | Outcome at $51 / 2$ years by week of gestational age among survivors in the EPIPAGE-2 study. Data corrected for study design and respondent selection. *Full scale intelligence quotient less than minus two standard deviations, with cut-off point of the distribution related to the reference sample born at term (37-41 weeks; web appendix 1). TSevere or moderate cerebral palsy (Gross Motor Function Classification System level $2-5$ ), vision (bilateral binocular visual acuity $<3.2 / 10$ ), hearing (unilateral-bilateral hearing loss $\geq 40 \mathrm{~dB}$ not corrected or partially corrected with hearing aid), and full scale intelligence quotient less than two standard deviations below the mean of the reference sample born at term (web appendix 1 ). $\mathrm{Cl}=$ confidence interval
Outcomes at age $51 / 2$ in this contemporary French national cohort of children born preterm in 2011 indicate that preterm birth continues to pose a large burden for families, healthcare, and educational systems. Although the rates of severe/moderate neurodevelopmental disabilities decreased with increasing gestational age, around $35 \%$ of the moderately to extremely preterm born children had mild disabilities. These children often used special care or educational services. A considerable proportion of parents had concerns about their child's development, particularly about behaviour. These concerns warrant attention.

\section{Strengths and limitations of the study}

Strengths of the EPIPAGE-2 study include the population based national cohort design with prospective enrolment of a large number of infants born not only extremely preterm but also very and moderately preterm. We used standardised developmental assessments to permit comparisons with other cohorts. Motor, sensory, and cognitive outcomes were used to describe rates of neurodevelopmental disabilities. Developmental coordination disorder and behavioural difficulties were included in the definition of mild disabilities to better reflect the complexity faced by preterm born children and their needs, which are rarely limited to intellectual deficits. ${ }^{36}$ We also report developmental interventions as they might have an important effect on family functioning ${ }^{37}$ and the need for health resources. Finally, scores for all tests are extra educational assistance and use of complex 


\begin{tabular}{|c|c|c|c|c|c|c|c|c|}
\hline & \multicolumn{7}{|c|}{ Preterm children } & \multirow[b]{3}{*}{$\begin{array}{l}\text { Reference } \\
\text { sample } \\
\text { born at term }\end{array}$} \\
\hline & \multicolumn{2}{|c|}{ 24-26 weeks } & \multicolumn{2}{|c|}{ 27-31 weeks } & \multicolumn{2}{|c|}{ 32-34 weeks } & \multirow[b]{2}{*}{$\begin{array}{l}P \text { for } \\
\text { trendt }\end{array}$} & \\
\hline & $\begin{array}{l}\text { No/total No, } \\
\%(95 \% \mathrm{Cl})\end{array}$ & $\begin{array}{l}\text { Multiple } \\
\text { imputation } \\
(\% ;(95 \% \mathrm{Cl}))\end{array}$ & $\begin{array}{l}\text { No/total No, } \\
\%(95 \% \mathrm{Cl})\end{array}$ & $\begin{array}{l}\text { Multiple } \\
\text { imputation } \\
(\% ;(95 \% \mathrm{Cl}))\end{array}$ & $\begin{array}{l}\text { No/total No, } \\
\%(95 \% \mathrm{Cl})\end{array}$ & $\begin{array}{l}\text { Multiple } \\
\text { imputation } \\
(\% ;(95 \% \mathrm{Cl}))\end{array}$ & & \\
\hline \multicolumn{9}{|l|}{ Education: } \\
\hline School enrolment & $\begin{array}{l}371 / 372,99.7 \\
(98.5 \text { to } 100)\end{array}$ & 99.3 (97.9 to 100$)$ & $\begin{array}{l}1881 / 1888,99.6 \\
(99.2 \text { to } 99.9)\end{array}$ & 99.2 (97.0 to 100$)$ & $755 / 755,100$ & 99.7 (97.3 to 100) & 0.05 & $\begin{array}{l}99.9 \\
(99.2 \text { to } 100)\end{array}$ \\
\hline \multicolumn{9}{|l|}{ Type of schooling: } \\
\hline No & 369 & - & 1862 & - & 749 & - & - & - \\
\hline $\begin{array}{l}\text { Mainstream class } \\
\text { without } \\
\text { support§ }\end{array}$ & $\begin{array}{l}78.6 \\
(74.0 \text { to } 82.7)\end{array}$ & $\begin{array}{l}72.7 \\
(68.3 \text { to } 77.1)\end{array}$ & 89.6 (88.2 to 91.0$)$ & 86.0 (84.1 to 87.9$)$ & $\begin{array}{l}95.5 \\
\text { (93.7 to 96.8) }\end{array}$ & $\begin{array}{l}93.3 \\
\text { (91.0 to 95.6) }\end{array}$ & \multirow{3}{*}{$<0.001 \neq$} & $\begin{array}{l}97.3 \\
(93.9 \text { to } 99.1)\end{array}$ \\
\hline $\begin{array}{l}\text { Mainstream class } \\
\text { with support§ }\end{array}$ & 19.5 (15.6 to 23.9$)$ & 24.0 (19.6 to 28.4$)$ & 9.7 (8.4 to 11.1$)$ & 12.6 (10.9 to 14.4$)$ & $\begin{array}{l}4.1 \\
(2.8 \text { to } 5.8)\end{array}$ & $6.0(4.0$ to 8.1$)$ & & 2.5 (0.8 to 6.0) \\
\hline $\begin{array}{l}\text { Special school } \\
\text { for children with } \\
\text { handicap }\end{array}$ & 1.9 (0.8 to 3.9) & 3.3 (1.5 to 5.1$)$ & $0.6(0.3$ to 1.1$)$ & 1.3 (0.7 to 2.0$)$ & $\begin{array}{l}0.4 \\
(0.1 \text { to } 1.2)\end{array}$ & 0.7 (0.0 to 1.5$)$ & & 0.1 (0.0 to 0.9$)$ \\
\hline \multicolumn{9}{|c|}{ Support§ or special school by group of neurodevelopmental disabilities ${ }^{\star \star}$ : } \\
\hline Severe NDD & 80.8 (60.6 to 93.4$)$ & $84.8(74.2$ to 95.4$)$ & $67.5(56.1$ to 77.6$)$ & $73.8(65.3$ to 82.4$)$ & $\begin{array}{l}44.4 \\
\text { (13.7 to } 78.8)\end{array}$ & $64.9(44.0$ to 85.8$)$ & 0.07 & $12.6(0.0$ to 79.9$)$ \\
\hline Moderate NDD & $47.4(31$ to 64.2$)$ & $54.3(41.6$ to 67.0$)$ & $31.3(24$ to 39.4$)$ & $38.4(31.5$ to 45.4$)$ & 15 (5.7 to 29.8$)$ & $24.1(12.4$ to 35.7$)$ & $<0.001$ & $19.2(0.6$ to 68.5$)$ \\
\hline Mild NDD & $16.3(10.4$ to 23.8$)$ & $19.9(13.5$ to 26.3$)$ & $7.7(5.6$ to 10.2$)$ & $10.5(7.9$ to 13.1$)$ & $3.9(1.7$ to 7.6$)$ & $6.1(2.7$ to 9.6$)$ & $<0.001$ & $4.5(1.0$ to 12.5$)$ \\
\hline None & 3.1 (0.8 to 7.7$)$ & $3.6(0.5$ to 6.8$)$ & $1.4(0.7$ to 2.4$)$ & 1.9 (0.9 to 2.9$)$ & $1.0(0.3$ to 2.6$)$ & 1.1 (0.1 to 2.2$)$ & 0.09 & 0 \\
\hline \multicolumn{9}{|c|}{ Complex developmental intervention: } \\
\hline No & 364 & - & 1846 & - & 742 & - & - & - \\
\hline $\begin{array}{l}\text { Psychologist or } \\
\text { psychiatristt† }\end{array}$ & 16.1 (12.5 to 20.3$)$ & 19.9 (15.3 to 24.5$)$ & 11.7 (10.3 to 13.2 ) & 15.1 (12.9 to 17.3$)$ & $8.2(6.3$ to 10.4$)$ & 11.7 (8.8 to 14.5 ) & $<0.001$ & 8.8 (5.8 to 12.6$)$ \\
\hline Orthoptistt† & $13.3(9.9$ to 17.3$)$ & 14.9 (10.8 to 18.9$)$ & $8.0(6.8$ to 9.4$)$ & $9.3(7.3$ to 11.3$)$ & $4.9(3.5$ to 6.8$)$ & $6.3(4.0$ to 8.7$)$ & $<0.001$ & $4.8(2.5$ to 8.3$)$ \\
\hline $\begin{array}{l}\text { Speech } \\
\text { therapistt† }\end{array}$ & 31.1 (26.3 to 36.3$)$ & 34.3 (29.4 to 39.3$)$ & 16.5 (14.8 to 18.3$)$ & 19.4 (17.2 to 21.6$)$ & 14.1 (11.7 to 16.8$)$ & 17.1 (14.2 to 20.0$)$ & $<0.001$ & 13.9 (9.6 to 19.2$)$ \\
\hline $\begin{array}{l}\text { Psychomotor } \\
\text { therapisttt }\end{array}$ & 23.6 (19.3 to 28.4 ) & 29.9 (24.3 to 35.6$)$ & 11 (9.6 to 12.6$)$ & 15.4 (12.8 to 17.9$)$ & $3.4(2.2$ to 5.0$)$ & 7.0 (4.2 to 9.8$)$ & $<0.001$ & 3.3 (1.6 to 5.8$)$ \\
\hline Physiotherapist†† & $5.6(3.5$ to 8.5$)$ & 10.2 (6.6 to 13.8$)$ & $4.3(3.4$ to 5.4$)$ & $7.3(5.3$ to 9.4$)$ & $1.1(0.5$ to 2.1$)$ & 4.0 (1.9 to 6.1$)$ & $<0.001$ & $1.2(0.2$ to 3.8$)$ \\
\hline \multirow{2}{*}{$\begin{array}{l}\text { At least one } \\
\text { specialised } \\
\text { serviceł‡ }\end{array}$} & \multirow{2}{*}{$\begin{array}{l}187 / 364,51.4 \\
(46.1 \text { to } 56.6)\end{array}$} & \multirow[b]{2}{*}{51.9 (46.4 to 57.3$)$} & $605 / 1846$ & \multirow[b]{2}{*}{$33.3(30.3$ to 36.2$)$} & \multirow{2}{*}{$\begin{array}{l}189 / 742,25.5 \\
(22.4 \text { to } 28.8)\end{array}$} & \multirow[b]{2}{*}{25.6 (21.8 to 29.4$)$} & \multirow[b]{2}{*}{-} & \multirow[b]{2}{*}{24.7 (19.6 to 30.4) } \\
\hline & & & 32.8 (30.6 to 35.0$)$ & & & & & \\
\hline Severe NDD** & $85.2(66.3$ to 95.8$)$ & 77.5 (57.0 to 98.0$)$ & 79.3 (68.9 to 87.4) & 71.6 (56.9 to 86.4$)$ & $55.6(21.2$ to 86.3$)$ & $60.0(34.5$ to 85.5$)$ & 0.17 & 79.0 (22.1 to 99.7) \\
\hline $\begin{array}{l}\text { Moderate } \\
\text { NDD** }^{* *}\end{array}$ & $63.9(46.2$ to 79.2$)$ & 65.9 (53.4 to 78.3$)$ & 60.1 (51.8 to 68.1$)$ & 56.2 (49.4 to 63.0) & 27.5 (14.6 to 43.9) & 35.1 (22.4 to 47.9) & $<0.001$ & 60.1 (24.6 to 89.0) \\
\hline Mild NDD** & $54.0(44.9$ to 62.9$)$ & $54.2(46.1$ to 62.3$)$ & 35.5 (31.6 to 39.7) & 34.3 (29.7 to 38.9) & $37.3(30.6$ to 44.4$)$ & $32.0(25.6$ to 38.4$)$ & $<0.001$ & $43.3(30.0$ to 57.3$)$ \\
\hline None & 33.8 (25.8 to 42.7$)$ & 33.6 (25.7 to 41.5) & 20.7 (18.0 to 23.7) & 20.8 (18.2 to 23.4$)$ & 18.9 (15.2 to 23.2$)$ & 18.3 (14.6 to 22.0$)$ & 0.003 & 15.8 (11.4 to 21.0$)$ \\
\hline Request to MDPH & $\begin{array}{l}100 / 368,27.2 \\
(22.7 \text { to } 32.0) \\
\end{array}$ & 31.1 (25.9 to 36.2 ) & $\begin{array}{l}262 / 1849,14.2 \\
(12.6 \text { to } 15.8)\end{array}$ & 17.1 (14.8 to 19.3$)$ & $\begin{array}{l}44 / 739,6.0 \\
(4.4 \text { to } 7.9)\end{array}$ & 7.8 (5.4 to 10.2$)$ & $<0.001$ & $6.0(3.1$ to 10.4$)$ \\
\hline \multicolumn{9}{|c|}{ 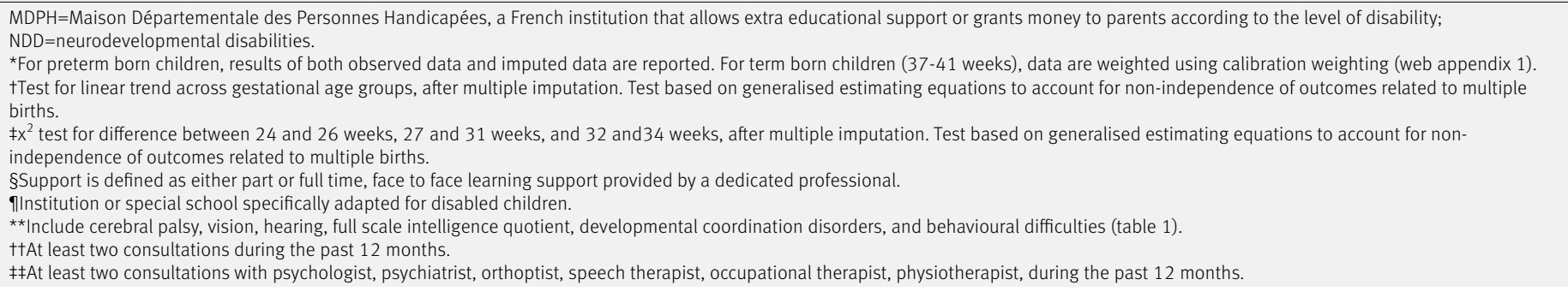 } \\
\hline
\end{tabular}

reported with reference to a sample of contemporary, term born children, examined with the same protocol.

The main limitations are the selection biases inherent in long term follow-up studies. Loss to followup among preterm born children particularly affected families with lower socioeconomic status, younger mothers, and children born at 32-34 weeks. We used multiple imputation to account for these missing data, resulting in an increase in cognitive disabilities in all gestational age groups, compatible with the impact of socioeconomic status on development. ${ }^{38}$ The reference sample was weighted to account for non-representativeness of the total ELFE cohort for the French population. Residual differences in outcomes were noted between the reference sample and the total ELFE cohort, however, suggesting selective participation of worried parents. Importantly, interpretations of trends across preterm populations are not affected by these concerns. We did not perform any comparisons between the preterm groups and the reference sample owing to the different methods used to take into account missing data in preterm groups and the reference sample. Owing to the reference sample selection bias, however, differences between preterm and term born groups are probably underestimated. Finally, assessors were not blinded to the gestational 


\begin{tabular}{|c|c|c|c|c|c|c|c|c|}
\hline \multirow{3}{*}{$\begin{array}{l}\text { Parents' } \\
\text { concerns } \\
\text { about child } \\
\text { development }\end{array}$} & \multicolumn{7}{|c|}{ Preterm children } & \multirow[b]{3}{*}{$\begin{array}{l}\text { Reference sample } \\
\text { born at term }\end{array}$} \\
\hline & \multicolumn{2}{|c|}{ 24-26 weeks } & \multicolumn{2}{|c|}{ 27-31 weeks } & \multicolumn{2}{|c|}{ 32-34 weeks } & \multirow[b]{2}{*}{$\begin{array}{l}P \text { for } \\
\text { trendt }\end{array}$} & \\
\hline & $\begin{array}{l}\text { No/total No, } \\
\%(95 \% \mathrm{Cl})\end{array}$ & $\begin{array}{l}\text { Multiple imputation } \\
(\% ;(95 \% \mathrm{Cl}))\end{array}$ & $\begin{array}{l}\text { No/total No, } \\
\%(95 \% \mathrm{Cl})\end{array}$ & $\begin{array}{l}\text { Multiple imputation } \\
(\% ;(95 \% \mathrm{CI}))\end{array}$ & $\begin{array}{l}\text { No/total No, } \\
\%(95 \% \mathrm{Cl})\end{array}$ & $\begin{array}{l}\text { Multiple imputation } \\
(\% ;(95 \% \mathrm{CI}))\end{array}$ & & \\
\hline No & 364 & - & 1814 & - & 724 & - & - & - \\
\hline Speech & 20.9 (16.8 to 25.4$)$ & 24.1 (19.4 to 28.7 ) & 15.2 (13.6 to 16.9$)$ & $17.5(15.5$ to 19.4$)$ & 13.9 (11.5 to 16.6$)$ & 15.6 (12.7 to 18.4$)$ & 0.002 & 14.9 (10.4 to 20.3$)$ \\
\hline Coordination & $16.3(12.7$ to 20.6$)$ & 17.6 (13.7 to 21.4$)$ & 11.6 (10.1 to 13.1$)$ & $12.4(10.5$ to 14.3$)$ & $4.8(3.3$ to 6.6$)$ & $5.4(3.5$ to 7.3$)$ & $<0.001$ & $4.4(2.0$ to 8.5$)$ \\
\hline Learning & $25.6(21.2$ to 30.4$)$ & $28.6(24.1$ to 33.1$)$ & 18.6 (16.8 to 20.4$)$ & 20.4 (18.1 to 22.7$)$ & $9.7(7.7$ to 12.1$)$ & 11.1 (8.5 to 13.6$)$ & $<0.001$ & $9.7(6.2$ to 14.2$)$ \\
\hline Behaviour & $41.4(36.3$ to 46.6$)$ & 44.5 (39.6 to 49.4$)$ & 29.4 (27.4 to 31.6$)$ & $31.6(29.3$ to 33.9$)$ & 21.3 (18.4 to 24.4$)$ & 23.2 (20.2 to 26.2$)$ & $<0.001$ & $25.4(20.1$ to 31.3$)$ \\
\hline $\begin{array}{l}\text { At least one } \\
\text { concern }\end{array}$ & $\begin{array}{l}202 / 364,55.5 \\
(50.2 \text { to } 60.7)\end{array}$ & 57.4 (52.6 to 62.2$)$ & $\begin{array}{l}742 / 1814,40.9 \\
(38.6 \text { to } 43.2)\end{array}$ & $42.8(40.4$ to 45.2$)$ & $\begin{array}{l}222 / 724,30.7 \\
(27.3 \text { to } 34.2)\end{array}$ & 32.9 (29.3 to 36.5$)$ & $<0.001$ & $32.8(27.1$ to 39.0$)$ \\
\hline \multicolumn{9}{|l|}{ By group of NDD‡: } \\
\hline Severe NDD & $92.3(74.9$ to 99.1$)$ & 88.0 (78.1 to 97.8$)$ & 82.7 (72.7 to 90.2) & 84.0 (76.6 to 91.5$)$ & $100(-)$ & 83.4 (66.6 to 100$)$ & 0.48 & $100(-)$ \\
\hline Moderate NDD & $81.6(65.7$ to 92.3$)$ & 79.9 (69.1 to 90.6$)$ & 66.9 (58.6 to 74.5$)$ & $68.6(62.4$ to 74.7$)$ & 56.4 (39.6 to 72.2$)$ & 57.9 (45.3 to 70.5$)$ & 0.012 & 90.2 (53.3 to 99.8$)$ \\
\hline Mild NDD & $63.0(54.0$ to 71.4$)$ & 60.5 (52.7 to 68.3$)$ & $52.5(48.2$ to 56.8$)$ & $50.2(46.4$ to 54.0$)$ & 48.5 (41.3 to 55.7$)$ & 44.5 (38.5 to 50.4$)$ & 0.002 & 52.5 (38.6 to 66.0$)$ \\
\hline None & 33.1 (25.0 to 42.0 ) & 32.6 (24.8 to 40.3$)$ & $24.0(21.1$ to 27.1$)$ & $24.1(21.2$ to 27.1$)$ & 18.6 (14.8 to 22.9 ) & 18.9 (15.2 to 22.6$)$ & $<0.001$ & 21.3 (15.9 to 27.5$)$ \\
\hline \multicolumn{9}{|c|}{$\begin{array}{l}\text { NDD=neurodevelopmental disabilities. } \\
\text { *For preterm born children, results of both observed data and imputed data are reported. For term born children ( } 37-41 \text { weeks), data are weighted using calibration weighting (web appendix } 1 \text { ). } \\
\text { †Test for linear trend across gestational age groups, after multiple imputation. Test based on generalised estimating equations to account for non-independence of outcomes related to multiple } \\
\text { births. } \\
\text { fInclude cerebral palsy vision, hearing full scale intelligence quotient developmental coordination disorders, and behavioural difficulties (table } 1 \text { ). }\end{array}$} \\
\hline
\end{tabular}

ages of the children and this can be considered as another limitation.

\section{Comparison with other studies}

Reporting outcomes for children born preterm is challenging not only because completeness of reporting is difficult to achieve, ${ }^{39}$ but also because outcome measures have to be meaningful for both health professionals and policy makers and for children and parents. ${ }^{13}$ Two recent international Delphi surveys have defined themes to be reported in follow-up studies of preterm born children in high income settings. ${ }^{40} 41$ In the first, general gross motor and cognitive abilities as well as sensory impairments were recommended for inclusion in a core outcome set. ${ }^{40}$ The second study identified education and the effect of minor impairments as being top research priorities. ${ }^{41}$ Our definition of mild neurodevelopmental disabilities is in line with these recommendations. In comparison with the commonly used definition, this refined definition increased the proportions of children with mild disabilities but, interestingly, to a similar extent (around 5\% to 7\%) across gestational age groups. This allowed us to describe the complexity and potential burden of mild disabilities for children and families. Compared with previous cohort studies, ${ }^{2}$ including the first EPIPAGE study, ${ }^{42}$ proportions of children with behavioural difficulties were low in EPIPAGE-2. Owing to the selection bias of the reference sample, rates of behavioural difficulties were probably underestimated in preterm born children. Interestingly, a discrepancy was seen between proportions of parents reporting concerns about their child's behaviour and the proportions of children with behavioural difficulties as identified by the strengths and difficulties questionnaire. This is in accordance with a study exploring parents' perspectives of children born before 29 weeks, ${ }^{12}$ in which a large majority of parents had a favourable opinion about the personality and happiness of their child, but more than half, whose children were classified as having no neurodevelopmental disabilities, had concerns about their child's development, notably their behaviour.

Using our definition, survival without any neurodevelopmental disabilities at age $5 \frac{1}{2}$ increased from $10 \%$ at 24 weeks to $50 \%$ at 34 weeks with an unexpected decrease at 34 weeks that might be due to sampling fluctuations. Overall, rates of disabilities and school assistance among children born at 32-34 weeks are in line with other reports of children born moderately preterm. ${ }^{43-45}$ In many countries, including France, these children are excluded from follow-up programmes. $^{2846}$ Primary care practitioners need to be aware of the difficulties families might face and be alert to parental concerns in order to avoid delayed referrals to specialised services for these children. Although school support depends on educational organisations within individual countries, consistency in school achievement across international cohorts has been described. ${ }^{47}$ In EPIPAGE-2, the high proportion of children requiring extra educational assistance emphasises that preterm birth already has an important effect on educational systems at this early age. Educational professionals in the UK have reported poor knowledge about the needs of preterm born children, and most feel ill equipped to provide school support. ${ }^{48}$ This lack of understanding is probably true in France and other countries, emphasising the importance of disseminating resources to improve teachers' knowledge ${ }^{49}$ and thus enhance appropriate support for these children.

The proportions of children receiving complex developmental interventions were high, even among children with no, or mild, disabilities. These interventions indicate a high investment from parents, which might affect maternal economic status. ${ }^{50}$ Exploration of the nature of these interventions is important as multidisciplinary collaboration and coordination of care between professionals is far from excellent, and improvements have been advocated 


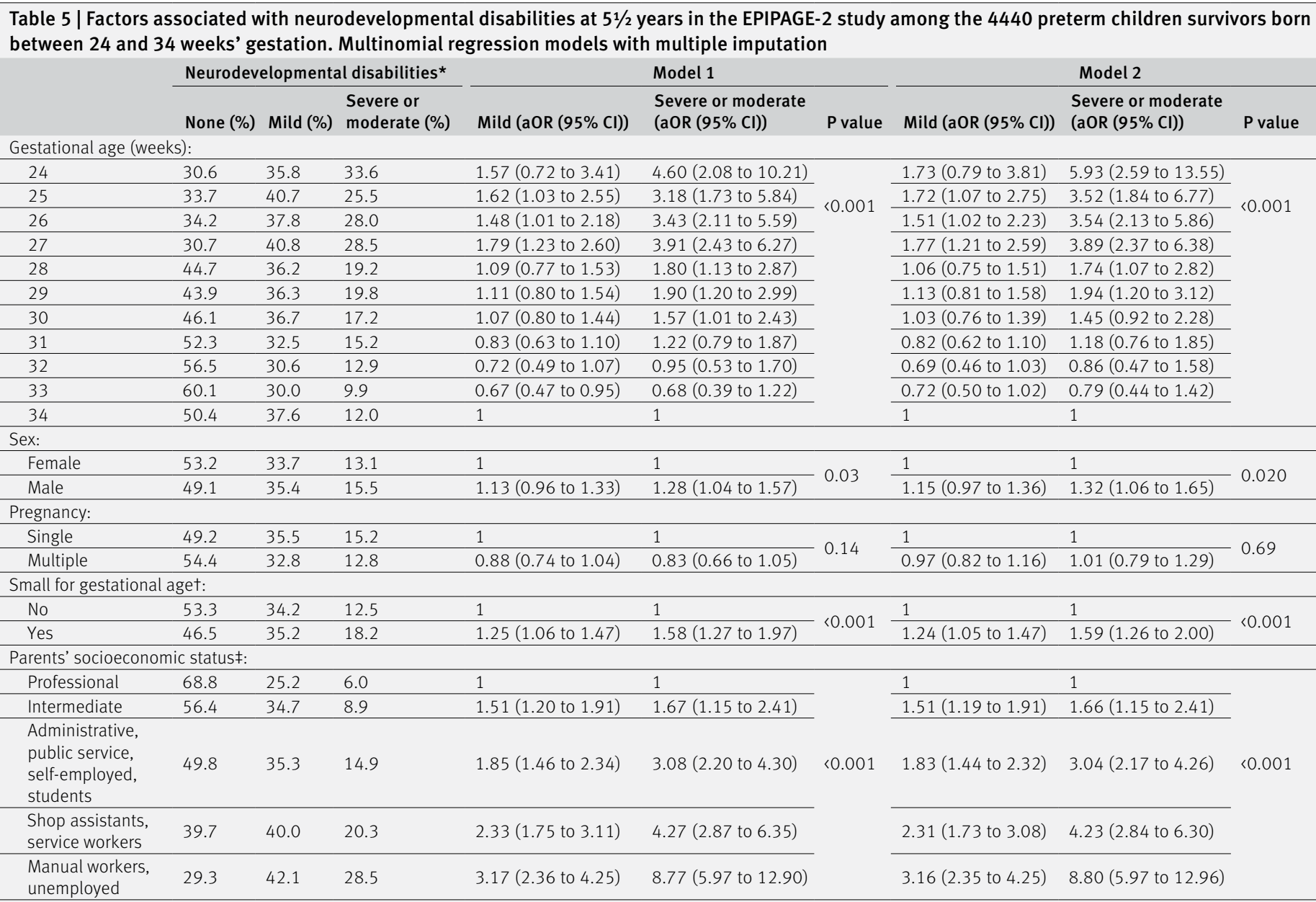

Model 1: adjusted for gestational age. Generalised estimating equations for multinomial outcome model to account for non-independence of outcomes related to multiple births.

Model 2: adjusted for gestational age, sex, single or multiple pregnancy, small for gestational age, and parents' socioeconomic status. Generalised estimating equations for multinomial outcome model to account for non-independence of outcomes related to multiple births.

*Include cerebral palsy, vision, hearing, full scale intelligence quotient, developmental coordination disorders, and behavioural difficulties (table 1).

+Small for gestational age was defined as birth weight less than the 10th centile for gestational age and sex based on French intrauterine growth curves. ${ }^{32}$

¥Defined as the highest occupational status between occupations of the mother and the father, or mother only if living alone.

by parents' associations to prevent families falling through gaps in care and to avoid needless duplication of treatment. ${ }^{37}$ Surprisingly, receipt of complex developmental interventions was not universal for children with severe/moderate neurodevelopmental disabilities, with a lower uptake of interventions in children with cognitive disabilities alone or with medical complexity, ${ }^{51} 52$ suggesting increased susceptibility to inequities in healthcare in these populations. In line with this, requests to the Maison Départementale des Personnes Handicapées might be considered low in comparison with rates of disability. The increased risk of neurodevelopment disabilities in families of low socioeconomic status should be recognised by screening programmes.

\section{Unanswered questions and future research}

Identifying developmental profiles to understand the aetiological pathways leading to neurodevelopmental disabilities and, therefore strategies for prevention or intervention, is an important area for research. ${ }^{53}$ Limited educational and health resources could focus on children most at risk, with follow-up according to a child's risk profile, and on improving information for parents to avoid unnecessary anxiety. Furthermore, understanding parental concerns about their child's development offers improved possibilities for identifying appropriate interventions.

\section{Conclusions}

In this large contemporary cohort of preterm born children, we report development at age $51 / 2$ in a broad range of areas, the need for educational assistance, complex developmental interventions, and parental concerns about their child's development. This global perspective is important when advising parents, health personnel, and teachers, and also when designing follow-up and intervention programmes for children born preterm. Extra educational assistance and complex developmental resources were often used, even for children born moderately preterm or with no, or mild, neurodevelopmental disabilities. Difficulties faced by these groups of children and their families should not be underestimated. 


\section{AUTHOR AFFILIATIONS}

${ }^{1}$ University of Paris, CRESS, Obstetrical Perinatal and Pediatric Epidemiology Research Team, EPOPé, INSERM, INRAE, F-75004 Paris, France

${ }^{2} \mathrm{CHU}$ Lille, Department of Neonatal Medicine, Jeanne de Flandre Hospital, Lille, France

${ }^{3}$ Department of Neonatal Medicine, Intensive Care, and Neuropediatrics, Rouen University Hospital, Rouen, France

${ }^{4}$ INSERM U1254, Neovascular Team, Perinatal Handicap, Institute of Biomedical Research and Innovation, Normandy University, Rouen, France

${ }^{5}$ INSERM U1027, SPHERE Team, France

${ }^{6}$ Toulouse 3 University Paul-Sabatier, Toulouse, France

${ }^{7}$ Clinical Epidemiology Unit, University Hospital Toulouse, Toulouse, France

${ }^{8}$ Department of Neonatal Medicine, Montpellier University Hospital, Montpellier, France

${ }^{9}$ Neonatal Intensive Care Unit, Grenoble Alps University Hospital, Grenoble, France

${ }^{10}$ UMR 5525 Techniques pour l'Evaluation et la Modélisation des Actions de la Santé, Centre National de la Recherche Scientifique, Techniques de l'Ingénierie Médicale et de la ComplexitéInformatique, Mathématiques et Applications, Grenoble Alps University, Grenoble, France

${ }^{11}$ French Institute for Demographic Studies, French Institute for Medical Research and Health, French Blood Agency, ELFE Joint Unit, Paris, France

${ }^{12}$ Department of Neonatology, North Hospital, Assistance Publique des Hôpitaux de Marseille, Marseille, France

${ }^{13}$ Port-Royal Maternity, Assistance Publique-Hôpitaux de Paris, Centre-University of Paris, Federation Hospitalo-Universitairefor prematurity, Paris, France

${ }^{14}$ Assistance Publique-Hôpitaux de Paris, University Hospital Necker-Enfants Malades, University of Paris, Paris, France

${ }^{15} \mathrm{UCL}$ Elizabeth Garrett Anderson Institute for Women's Health, University College London, London, UK

${ }^{16}$ Department of Neonatal Medicine, Nantes University Hospital, Nantes, France

${ }^{17}$ Clinical Epidemiology, Clinical Investigation Centre $\mathrm{CICOO} 4$ Nantes University Hospital, Nantes, France

${ }^{18}$ University of Paris, CRESS, Team Early Life Research on Later Health, UMR 1153, INSERM, INRAE, Villejuif, France

${ }^{19}$ Clinical Investigation Centre P1419, Assistance PubliqueHôpitaux de Paris, Paris, France

We are grateful for the participation of all families of preterm infants in the EPIPAGE-2 cohort study and for the cooperation of all maternity and neonatal units in France. We thank parents' associations (SOS Prema, Collectif Interassociatif Autour de la Naissance (CIANE), Jumeaux et plus, among others) for their overwhelming support and involvement in the dissemination of the results. We thank the EPIPAGE-2 study group for its substantial contribution to the conception, design, and acquisition of data. Details on the EPIPAGE-2 writing group and collaborators are in the web appendix list.

Contributors: VP, LM-M, and P-YA had full access to all the data in the study and take responsibility for the integrity of the data and the accuracy of the data analysis. VP, MK, ASM, ST, and SM conceptualised the study and wrote the manuscript. LM-M performed the statistical analysis. VB coordinated data collection and had responsibility for technical support. M-AC and P-YA obtained funding and supervised the study. All authors contributed to the analysis plan and interpretation of the results and reviewed and approved the final manuscript. All members of the writing group were involved in the regional organisation for data collection and reviewed or approved the final manuscript. All the listed authors met the ICMJE criteria for authorship. VP is the study guarantor. The corresponding author attests that all listed authors meet authorship criteria and that no others meeting the criteria have been omitted.

Funding: This project has been funded with support from the French Institute of Public Health Research/Institute of Public Health, and its partners. Partners include the French Health Ministry, National Institute of Health and Medical Research (INSERM), National Institute of Cancer, and National Solidarity Fund for Autonomy (CNSA); National Research Agency through the French EQUIPEX programme of investments in the future (reference ANR-11-EQPX-0038); PREMUP
Foundation; Foundation of France (reference 11779); Foundation for Medical Research (SPF20160936356); and hospital clinical research programme Epinutri (DGOS13-040). The funders had no role in the study design, data collection and analysis, decision to publish, or preparation of the manuscript.

Competing interests: All authors have completed the ICMJE uniform disclosure form at www.icmje.org/coi_disclosure.pdf and declare: support from the French Institute of Public Health Research/Institute of Public Health and its partners for the submitted work; no financial relationships with any organizations that might have an interest in the submitted work in the previous three years, no other relationships or activities that could appear to have influenced the submitted work.

Ethical approval: Assessments occurred only after families had received information and provided written informed consent. This study was approved by the National Data Protection Authority (CNIL DR-2016-290) and by appropriate ethics committees (Consultative Committee on the Treatment of Data on Personal Health for Research Purposes, reference No 16.263; Committee for the Protection of People Participating in Biomedical Research, reference 2016A00333-48).

Data sharing: The EPIPAGE studies are subject to a data sharing policy that can be downloaded from https://epipage2.inserm.fr

The lead author (the manuscript's guarantor) affirms that the manuscript is an honest, accurate, and transparent account of the study being reported; that no important aspects of the study have been omitted; and that any discrepancies from the study as planned have been explained.

Dissemination to participants and related patient and public communities: Results will be sent to families through newsletters and webinar. Media for dissemination will be available on request for the study group. A press conference will be organised for public communities. Funders receive annual reports.

Provenance and peer review: Not commissioned; externally peer reviewed.

This is an Open Access article distributed in accordance with the Creative Commons Attribution Non Commercial (CC BY-NC 4.0) license, which permits others to distribute, remix, adapt, build upon this work non-commercially, and license their derivative works on different terms, provided the original work is properly cited and the use is noncommercial. See: http://creativecommons.org/licenses/by-nc/4.0/.

1 Johnson S, Marlow N. Early and long-term outcome of infants born extremely preterm. Arch Dis Child 2017;102:97-102. doi:10.1136/ archdischild-2015-309581

2 Allotey J, Zamora J, Cheong-See F, et al. Cognitive, motor, behavioura and academic performances of children born preterm: a metaanalysis and systematic review involving 64061 children. BJOG 2018:125:16-25. doi:10.1111/1471-0528.14832

3 Marlow N, Wolke D, Bracewell MA, Samara M, EPICure Study Group. Neurologic and developmental disability at six years of age after extremely preterm birth. N Engl J Med 2005;352:9-19. doi:10.1056/ NEJMoa041367

4 Larroque B, Ancel P-Y, Marret S, et al, EPIPAGE Study group. Neurodevelopmental disabilities and special care of 5 -year-old children born before 33 weeks of gestation (the EPIPAGE study): a longitudinal cohort study. Lancet 2008;371:813-20. doi:10.1016/ S0140-6736(08)60380-3

5 Serenius F, Ewald U, Farooqi A, et al, Extremely Preterm Infants in Sweden Study Group. Neurodevelopmental Outcomes Among Extremely Preterm Infants 6.5 Years After Active Perinatal Care in Sweden. JAMA Pediatr 2016;170:954-63. doi:10.1001/ jamapediatrics.2016.1210

6 Cheong JLY, Anderson PJ, Burnett AC, et al, Victorian Infant Collaborative Study Group. Changing Neurodevelopment at 8 Years in Children Born Extremely Preterm Since the 1990 s. Pediatrics 2017;139:e20164086. doi:10.1542/peds.2016-4086

7 Holsti L, Grunau RVE, Whitfield MF. Developmental coordination disorder in extremely low birth weight children at nine years. J Dev Behav Pediatr 2002;23:9-15. doi:10.1097/00004703200202000-00002

8 Marlow N, Hennessy EM, Bracewell MA, Wolke D, EPICure Study Group. Motor and executive function at 6 years of age after extremely preterm birth. Pediatrics 2007;120:793-804. doi:10.1542/ peds.2007-0440

9 Roberts G, Anderson PJ, Davis N, De Luca C, Cheong J, Doyle LW, Victorian Infant Collaborative Study Group. Developmental coordination disorder in geographic cohorts of 8-year-old children born extremely preterm or extremely low birthweight in the 1990 s. Dev Med Child Neurol 2011:53:55-60. doi:10.1111/j.14698749.2010.03779.x 
10 Bolk J, Farooqi A, Hafström M, Åden U, Serenius F. Developmental Coordination Disorder and Its Association With Developmental Comorbidities at 6.5 Years in Apparently Healthy Children Born Extremely Preterm. JAMA Pediatr 2018;172:765-74. doi:10.1001/ jamapediatrics.2018.1394

11 Blank R, Barnett AL, Cairney J, et al. International clinical practice recommendations on the definition, diagnosis, assessment, intervention, and psychosocial aspects of developmental coordination disorder. Dev Med Child Neurol 2019;61:242-85. doi:10.1111/dmcn.14132

12 Jaworski M, Janvier A, Lefebvre F, Luu TM. Parental Perspectives Regarding Outcomes of Very Preterm Infants: Toward a Balanced Approach. J Pediatr 2018;200:58-63.e1. doi:10.1016/j.jpeds.2018.03.006

13 Webbe J, Brunton G, Ali S, Longford N, Modi N, Gale C, Core Outcomes in Neonatology (COIN) Project Steering Group. Parent, patient and clinician perceptions of outcomes during and following neonatal care: a systematic review of qualitative research. BMJ Paediatr Open 2018;2:e000343. doi:10.1136/bmjpo-2018-000343

14 Cheong JL, Spittle AJ, Burnett AC, Anderson PJ, Doyle LW. Have outcomes following extremely preterm birth improved over time?Semin Fetal Neonatal Med 2020;25:101114. doi:10.1016/j.siny.2020.101114

15 Costeloe KL, Hennessy EM, Haider S, Stacey F, Marlow N, Draper ES. Short term outcomes after extreme preterm birth in England comparison of two birth cohorts in 1995 and 2006 (the EPICure studies). BMJ 2012;345:e7976. doi:10.1136/bmj.e7976

16 Ancel P-Y, Goffinet F, Kuhn P, et al, EPIPAGE-2 Writing Group. Survival and morbidity of preterm children born at 22 through 34 weeks' gestation in France in 2011: results of the EPIPAGE-2 cohort study. JAMA Pediatr 2015;169:230-8. doi:10.1001/ jamapediatrics.2014.3351

17 Squarza C, Picciolini O, Gardon L, et al. Seven Years Cognitive Functioning and Early Assessment in Extremely Low Birth Weight Children. Front Psychol 2017;8:1257. doi:10.3389/fpsyg.2017.01257

18 Chan E, Leong P, Malouf R, Quigley MA. Long-term cognitive and school outcomes of late-preterm and early-term births: a systematic review. Child Care Health Dev 2016;42:297-312. doi:10.1111/cch.12320

19 Ancel P-Y, Goffinet F, EPIPAGE 2 Writing Group. EPIPAGE 2: a preterm birth cohort in France in 2011. BMC Pediatr 2014;14:97. doi:10.1186/1471-2431-14-97

20 Pierrat V, Marchand-Martin L, Arnaud C, et al, EPIPAGE-2 writing group. Neurodevelopmental outcome at 2 years for preterm children born at 22 to 34 weeks' gestation in France in 2011: EPIPAGE-2 cohort study. BMJ 2017:358:j3448. doi:10.1136/bmj.j3448

21 Brenner M, Kidston C, Hilliard C, et al. Children's complex care needs: a systematic concept analysis of multidisciplinary language. Eur J Pediatr 2018;177:1641-52. doi:10.1007/s00431-018-3216-9

22 Charles MA, Thierry X, Lanoe J-L, et al. Cohort Profile: The French national cohort of children (ELFE): birth to 5 years. Int J Epidemiol 2020;49:368-369j. doi:10.1093/ije/dyz227

23 Surveillance of Cerebral Palsy in Europe. Surveillance of cerebral palsy in Europe: a collaboration of cerebral palsy surveys and registers. Dev Med Child Neurol 2000;42:816-24. doi:10.1017/ s0012162200001511

24 Ghassabian A, Sundaram R, Bell E, Bello SC, Kus C, Yeung E. Gross Motor Milestones and Subsequent Development. Pediatrics 2016;138:e20154372-20154372. doi:10.1542/ peds.2015-4372

25 Brown T. Movement Assessment Battery for Children. In: Volkmar FR, ed. Encyclopedia of Autism Spectrum Disorders. 2nd ed. Springer New York, 2013: 1925-39, doi:10.1007/978-1-4419-1698 3_1922, MABC-2

26 Zanlonghi X, Avital S, Sander MS, et al. Comparaison de deux échelles logarithmique d'acuité visuelle de loin pour l'enfant: Rossano et Sander-Zanlonghi. J Français D'orthoptique 1999;31:199-216.

27 WHO. Vision impairment and blindness. 2021. https://www.who.int/ news-room/fact-sheets/detail/blindness-and-visual-impairment.

28 NICE. Developmental follow-up of children and young people born preterm. NICE guidelines 2017. https://www.nice.org.uk/guidance/ ng72

29 Pearson Clinical \& Talent Assessment. WPPSI-IV - Wechsler Intelligence Scale for Children - 4th ed. https://www.pearsonclinical. $\mathrm{fr} /$ wppsi-iv-echelle-dintelligence-de-wechsler-pour-la-periode-prescolaire-et-primaire-quatrieme-edition.

30 Goodman R. The Strengths and Difficulties Questionnaire: a research note. J Child Psychol Psychiatry 1997;38:581-6. doi:10.1111/j.1469-7610.1997.tb01545.x

31 Goodman R. Psychometric properties of the strengths and difficulties questionnaire. J Am Acad Child Adolesc Psychiatry 2001;40:133745. doi:10.1097/00004583-200111000-00015

32 Ego A, Prunet C, Lebreton E, et al. [Customized and non-customized French intrauterine growth curves. I - Methodology]. J Gynecol Obstet Biol Reprod (Paris) 2016;45:155-64. doi:10.1016/j. jgyn.2015.08.009

33 Squires J, Bricker D. Ages \& Stages Questionnaires (ASQ-3): A ParentCompleted Child-Monitoring System. 3rd ed. Stanford: Paul Brookes
Publishing Co, 2009. https://products.brookespublishing.com/AgesStages-Questionnaires-Third-Edition-ASQ-3-P569.aspx

34 White IR, Royston P, Wood AM. Multiple imputation using chained equations: Issues and guidance for practice. Stat Med 2011;30:377 99. doi:10.1002/sim.4067

35 Rubin DB. Frontmatter. In: Multiple Imputation for Nonresponse in Surveys. John Wiley \& Sons, Inc, 1987: i-xxix, doi:10.1002/9780470316696.fmatter.

36 Johnson S, Strauss V, Gilmore C, Jaekel J, Marlow N, Wolke D. Learning disabilities among extremely preterm children without neurosensory impairment: Comorbidity, neuropsychological profiles and scholastic outcomes. Early Hum Dev 2016;103:69-75. doi:10.1016/j. earlhumdev.2016.07.009

37 Koldewijn K, Wolf MJ, Pierrat V, van Wassenaer-Leemhuis A, Wolke D. European Standards of Care for Newborn Health. Post-discharge responsive parenting programmes. 2018. https://newborn-healthstandards.org/responsive-parenting-programme/

38 Potijk MR, Kerstjens JM, Bos AF, Reijneveld SA, de Winter AF Developmental delay in moderately preterm-born children with low socioeconomic status: risks multiply. J Pediatr 2013;163:1289-95. doi:10.1016/j.jpeds.2013.07.001

39 Ding S, Mew EJ, Chee-A-Tow A, Offringa M, Butcher NJ, Moore GP. Neurodevelopmental outcome descriptions in cohorts of extremely preterm children. Arch Dis Child Fetal Neonatal Ed 2020;105:510-9. doi:10.1136/archdischild-2019-318144

40 Webbe JWH, Duffy JMN, Afonso E, et al. Core outcomes in neonatology: development of a core outcome set for neonatal research. Arch Dis Child Fetal Neonatal Ed 2020;105:425-31. doi:10.1136/archdischild-2019-317501

41 Zeitlin J, Sentenac M, Morgan AS, et al, RECAP Preterm child cohort research group. Priorities for collaborative research using very preterm birth cohorts. Arch Dis Child Fetal Neonatal Ed 2020:105:538-44 doi:10.1136/archdischild-2019-317991

42 Delobel-Ayoub M, Arnaud C, White-Koning M, et al, EPIPAGE Study Group. Behavioral problems and cognitive performance at 5 years of age after very preterm birth: the EPIPAGE Study. Pediatrics 2009;123:1485-92. doi:10.1542/peds.2008-1216

43 Potijk MR, de Winter AF, Bos AF, Kerstjens JM, Reijneveld SA. Cooccurrence of developmental and behavioural problems in moderate to late preterm-born children. Arch Dis Child 2016;101:217-22. doi:10.1136/archdischild-2015-308958

44 Pritchard VE, Clark CAC, Liberty K, Champion PR, Wilson K, Woodward LJ. Early school-based learning difficulties in children born very preterm. Early Hum Dev 2009;85:215-24. doi:10.1016/j. earlhumdev.2008.10.004

45 Quigley MA, Poulsen G, Boyle E, et al. Early term and late preterm birth are associated with poorer school performance at age 5 years: a cohort study. Arch Dis Child Fetal Neonatal Ed 2012;97:F167-73. doi:10.1136/archdischild-2011-300888

46 HAS. [Neurodevelopmental Disorders - Identification and Referral of Children at Risk]. https://www.has-sante.fr/jcms/p_3161334/ $\mathrm{fr} /$ troubles-du-neurodeveloppement-reperage-et-orientation-desenfants-a-risque.

47 Saigal S, den Ouden L, Wolke D, et al. School-age outcomes in children who were extremely low birth weight from four international population-based cohorts. Pediatrics 2003;112:943-50. doi:10.1542/peds.112.4.943

48 Johnson S, Gilmore C, Gallimore I, Jaekel J, Wolke D. The long-term consequences of preterm birth: what do teachers know?Dev Med Child Neurol 2015;57:571-7. doi:10.1111/dmcn.12683

49 Johnson S, Bamber D, Bountziouka V, et al. Improving developmenta and educational support for children born preterm: evaluation of an e-learning resource for education professionals. BMJ Open 2019;9:e029720. doi:10.1136/bmjopen-2019-029720

50 Saurel-Cubizolles M-J, Marchand-Martin L, Pierrat V, et al. Maternal employment and socio-economic status of families raising children born very preterm with motor or cognitive impairments: the EPIPAGE cohort study. Dev Med Child Neurol 2020;62:1182-90. doi:10.1111/dmcn.14587

51 Mills IS, Doyle LW, Cheong JL, Roberts G, Victorian Infant Collaborative Study Group. Rates of early intervention services in children born extremely preterm/extremely low birthweight. J Paediatr Child Health 2018:54:74-9. doi:10.1111/jpc.13668

52 Kuo DZ, Goudie A, Cohen E, et al. Inequities in health care needs for children with medical complexity. Health Aff (Millwood) 2014;33:2190-8. doi:10.1377/hlthaff.2014.0273

53 Johnson S, Waheed G, Manktelow BN, et al. Differentiating the Preterm Phenotype: Distinct Profiles of Cognitive and Behaviora Development Following Late and Moderately Preterm Birth. J Pediatr 2018;193:85-92.e1. doi:10.1016/j.jpeds.2017.10.002

Web appendix 1: Appendices

Web appendix list: EPIPAGE-2 writing group and collaborators 